\title{
Inflammation, immunosuppressive microenvironment and breast cancer: opportunities for cancer prevention and therapy
}

\author{
Sachin Kumar Deshmukh ${ }^{1,2}$, Sanjeev Kumar Srivastava, ${ }^{1,2}$, Teja Poosarla ${ }^{1}$, Donna Lynn Dyess ${ }^{1}$, \\ Nicolette Paolaungthong Holliday ${ }^{3}$, Ajay Pratap Singh ${ }^{1,2,4}$, Seema Singh ${ }^{1,2,4}$ \\ ${ }^{1}$ Mitchell Cancer Institute, ${ }^{2}$ Department of Pathology, ${ }^{3}$ Department of Obstetrics and Gynecology, University of South Alabama, Mobile, AL, USA; \\ ${ }^{4}$ Department of Biochemistry and Molecular Biology, College of Medicine, University of South Alabama, Mobile, AL, USA \\ Contributions: (I) Conception and Design: S Singh, AP Singh, SK Deshmukh; (II) Administrative support: S Singh, AP Singh; (III) Provision of study \\ materials or patients: None; (IV) Collection and assembly of data: SK Deshmukh, SK Srivastava; (V) Data analysis and interpretation: All authors; (VI) \\ Manuscript writing: All authors; (VII) Final Approval of manuscript: All authors. \\ Correspondence to: Seema Singh, PhD. Associate Professor, Department of Pathology, College of Medicine, Cancer Biology Program, Mitchell Cancer \\ Institute, University of South Alabama, 1660 Springhill Avenue, Mobile, AL 36604-1405, USA. Email: seemasingh@health.southalabama.edu.
}

\begin{abstract}
Breast cancer is the most commonly diagnosed malignancy and a leading cause of cancerrelated death in women worldwide. It also exhibits pronounced racial disparities in terms of incidence and clinical outcomes. There has been a growing interest in research community to better understand the role of the microenvironment in cancer. Several lines of evidence have highlighted the significance of chronic inflammation at the local and/or systemic level in breast tumor pathobiology. Inflammation can influence breast cancer progression, metastasis and therapeutic outcome by establishing a tumor supportive immune microenvironment. These processes are mediated through a variety of cytokines and hormones that exert their biological actions either locally or distantly via systemic circulation. Targeting of immune and inflammatory pathways has met tremendous success in some cancers underscoring the importance of research to further our understanding of these systems in breast cancer. This knowledge can be helpful not only in the development of novel prevention and therapeutic strategies, but also help in better prediction of therapeutic responses in patients. This review summarizes some of the significant findings on the role of inflammation in breast cancer to gain collective molecular and mechanistic insights. We also discuss ongoing efforts and future outlook to exploit the existing knowledge for improved breast cancer management.
\end{abstract}

Keywords: Breast cancer (BC); inflammation; immune suppression; tumor microenvironment (TME)

Submitted Sep 05, 2019. Accepted for publication Sep 09, 2019.

doi: 10.21037/atm.2019.09.68

View this article at: http://dx.doi.org/10.21037/atm.2019.09.68

\section{Introduction}

Breast cancer $(\mathrm{BC})$ remains the foremost cause of cancerrelated death and most frequently diagnosed non-cutaneous malignancy in women in the United States and worldwide (1). According to an estimate by American Cancer Society, this year 268,600 women are expected to be diagnosed with BC and about 41,760 will die because of it in the United States (2). Moreover, an increase in BC incidence has been reported in recent decades among women who are older than 50 years of age, while a reduced rate of survival is reported for women below 50 years (3-5). Furthermore, significant race-associated disparities in $\mathrm{BC}$ incidence and clinical outcomes has also been reported $(6,7)$. Women of African origin are affected most disproportionately exhibiting an early onset of disease, more likely diagnosis of aggressive $\mathrm{BC}$ subtypes and significantly greater mortality $(8,9)$. In the past, overall incidence rate of $\mathrm{BC}$ used to be lower in African American women than that in Caucasian women, but it is catching up fast, while mortality gap continues to widen between these racial groups (10-12).

Many risk factors have been recognized for BC development including advancing age, family history, 


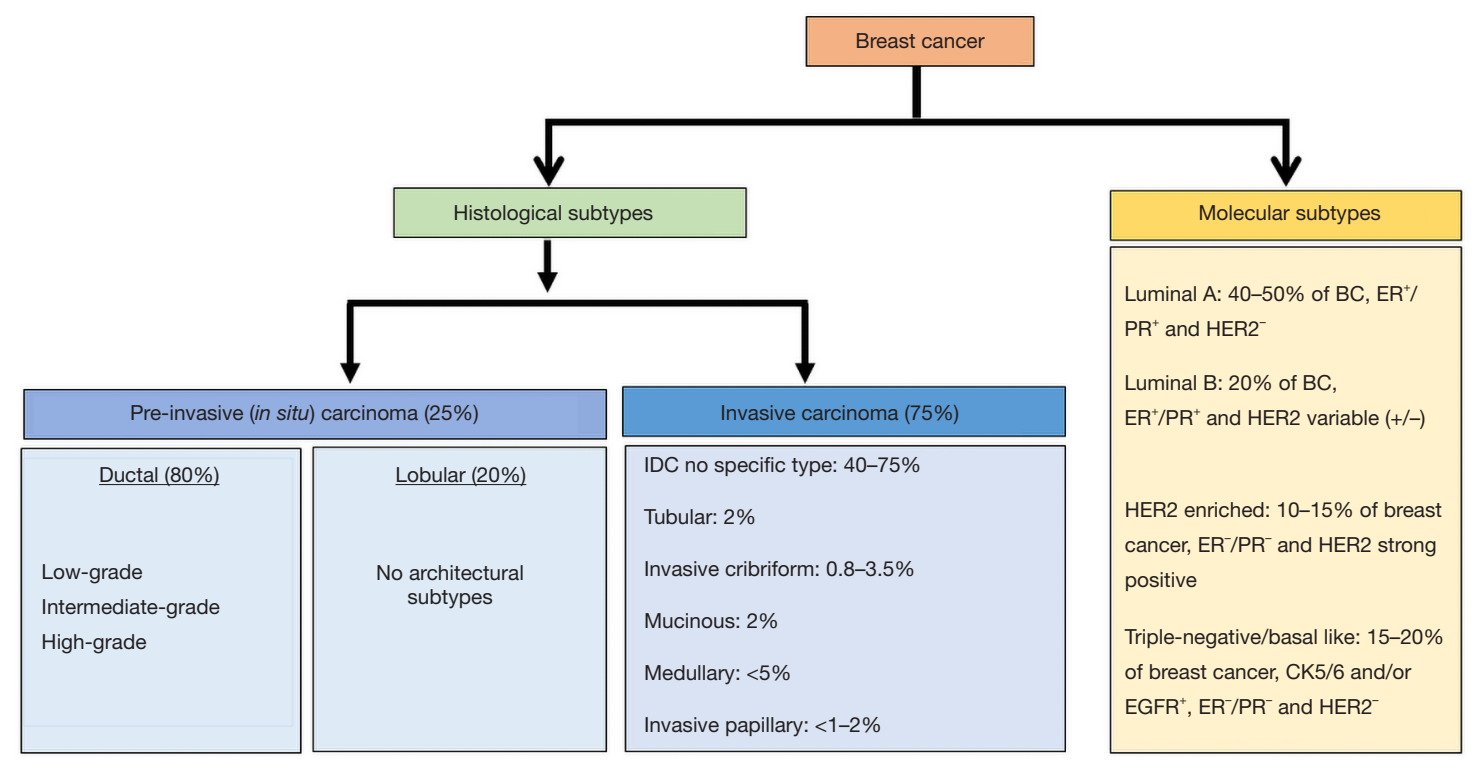

Figure 1 Histological and molecular classification of breast cancer. Classification is based on architectural features, growth pattern and the genetic landscape of breast tumors. IDC, invasive ductal carcinoma.

certain genetic mutations (such as $\mathrm{BC}$ gene, $B R C A 1$ and $B R A C A 2)$, obesity and drinking habits to name a few (13-15). Chronic inflammation at the local and systemic level has also been suggested to be an important driver of $\mathrm{BC}(16,17)$. Indeed, tumor development is a complex and evolutionary process that involves changes not only in the tumor initiating cells, but also in the surrounding environment comprising of other cells and secreted biomolecules $(18,19)$. An inflammatory tumor microenvironment (TME) can influence $\mathrm{BC}$ progression in various ways and numerous studies have been conducted to better understand the role of inflammatory pathways in BC pathobiology. In this review, we will discuss findings pertinent to the role of inflammation in $\mathrm{BC}$ to gain collective molecular and mechanistic insights and envision how this knowledge could be translated into strategies for disease prevention and therapy.

\section{BC: histological and molecular subtypes}

$\mathrm{BC}$ is a heterogeneous group of neoplasms. The disease can differ greatly at the histological and molecular levels among cancer-bearing individuals and also within a single tumor $(20,21)$. Considering this high degree of diversity, breast tumors are classified into various histological and molecular subtypes for their effective clinical management (Figure 1).

\section{Histological subtypes}

Based on their histological features, breast tumors are largely divided into two subtypes, pre-invasive or in situ breast carcinoma and invasive breast carcinoma.

\section{Pre-invasive (in situ) breast carcinoma}

The in situ breast carcinoma is referred to the localized cancer that has not spread beyond the primary site. It is further sub-classified as either ductal carcinoma in situ (DCIS) or lobular carcinoma in situ (LCIS). DCIS is diagnosed more commonly in the United States than LCIS accounting (22-24). It is characterized by BC cells that are restricted to the lining of the milk ducts and have not invaded into the surrounding breast tissue or any other parts of the body. However, if left untreated, it can spread to nearby tissue over time, and develop into an invasive BC. On the basis of histological appearance, DCIS is further subdivided into several subtypes including micropapillary, papillary, solid, cribriform and comedo $(25,26)$. LCIS, on the other hand, develops in the lobules and usually does not ever spread to the surrounding breast tissue (24), although patients with LCIS remain at higher risk of developing BC. About $20-25 \%$ of women with LCIS are estimated to develop some form of invasive BC (either lobular or infiltrating ductal carcinoma) within her lifetime $(24,27)$. 


\section{Invasive breast carcinoma}

As the nomenclature suggests, this cancer histological type has invaded into the surrounding breast tissues at the time of diagnosis. Also, similar to in situ carcinomas, invasive carcinomas are a group of tumors that are further categorized into several histological subtypes, such as infiltrating ductal, invasive lobular, ductal/lobular, mucinous (colloid), tubular, medullary and papillary carcinomas. Of these, invasive ductal carcinoma (IDC), which develops in the milk ducts and spreads to the fatty tissue of the breast outside the duct, is the most common and accounts for about $70-80 \%$ of all invasive lesions $(28,29)$. IDC is further sub-classified based on mitotic index, nuclear pleomorphism, and glandular/tubule formation into welldifferentiated (grade 1), moderately differentiated (grade 2) or poorly differentiated (grade 3) carcinomas (28). Unlike DCIS, where the use of molecular markers including estrogen receptor (ER), progesterone receptor (PR), and HER2/neu is still a subject of debate, IDC sub-classification based on the molecular markers is well accepted (30).

\section{Molecular subtypes}

Classification of BC based on molecular components is more useful than that based on histology for the treatment planning and development of newer targeted therapies. It is achieved by obtaining the molecular and genetic information from the cancerous breast tissue. Broadly, five major molecular subtypes of $\mathrm{BC}$ have been defined that include luminal A, luminal B, triple-negative or basal-like, HER2-enriched and normal-like. Two additional molecular subtypes that are less common and poorly described are claudin-low and molecular apocrine BC. The claudin-low $\mathrm{BC}$ has low-to-absent expression of luminal markers and elevated expression of epithelial-mesenchymal transition (EMT) markers, whereas molecular apocrine tumors are characterized by an ER negative/androgen receptor (AR) positive phenotype $(31,32)$.

\section{Luminal A}

This subtype is hormone-receptor positive $\left(\mathrm{ER}^{+}\right.$and/ or $\mathrm{PR}^{+}$) and HER2 negative. It also expresses low levels of $\mathrm{Ki}-67$ protein. Tumors of this subtype are low-grade, grow slowly and have the best outcomes among all other molecular sub-types $(32,33)$.

\section{Luminal B}

This subtype is hormone-receptor positive, but can be either HER2 positive or HER2 negative with high Ki-67 levels. Tumors of this subtype grow slightly faster, have poorer tumor grade and poorer prognosis as compared to subtype luminal A $(32,33)$.

\section{Triple-negative BC (TNBC)/basal-like}

This subtype is estrogen-receptor, progesterone-receptor and HER2 negative. It is considered the most aggressive. Also, for not yet established reasons, this subtype is more common among younger African American women $(26,32,33)$.

\section{HER2-enriched}

This subtype is hormone-receptor negative, but HER2 positive. Tumors of this molecular subtype grow faster than luminal A and B subtypes; however, can be effectively treated with anti-HER2 drugs such as trastuzumab (herceptin) $(26,32,33)$.

\section{Normal-like}

This subtype is hormone-receptor positive, HER2 negative, and has low levels of KI-67. Their prognosis is generally good, but slightly worse than luminal A subtype $(26,32,34)$.

\section{Inflammation and inflammatory mediators}

Inflammation is a process by which our immune system protects us from foreign invaders, such as viruses and bacteria, and helps in the healing and repair of the damaged tissue. However, if not regulated correctly and remained prolonged (chronic inflammation), it can actually contribute to the development of diseases including BC $(16,17)$. Chronic inflammation can be induced by abnormal immune reactions, infections that perpetuate, or conditions such as obesity. In obese condition, excessive accumulation of macronutrients in the adipose tissues stimulates the release of inflammatory mediators to maintain the tissue homeostasis, thus creating a pro-inflammatory tumor supportive environment. Similarly, poor lifestyle (smoking habit, unhealthy diet, alcohol overuse, etc.) and inadequate relief of chronic stress can also lead to longterm inflammation and contribute to the development, progression, and recurrence of $\mathrm{BC}$ (35-37). Indeed, inflammatory $\mathrm{BC}$, a rare type of cancer often negative for triple receptors, develops rapidly and is considered one of the most aggressive BC subtype (38-40).

Chronic inflammation is mediated through a variety of cytokines and hormones, which also contribute to BC 
progression, metastasis and therapy-resistance in various ways. These inflammatory mediators are the cell and/ or plasma-derived soluble and diffusible molecules that exert their biological actions either locally or distantly via systemic circulation. Some of the important categories of inflammatory mediators are described below:

\section{Complement system and kinins}

The complement system is a collection of soluble proteins and membrane receptors in the bloodstream that works together to destroy the pathogens, provoke inflammatory reactions, and remove debris from cells and tissues. The complement systems proteins are numerically labeled with the prefix C (e.g., C1-C9) and are primarily synthesized in the liver. These proteins are largely enzyme precursors which catalyze a series of enzymatic reactions leading to the formation of products that have multiple immune effects. The mediators of inflammation in complement system include complement and complement-derived peptides (mainly C3 and C5) and kinins (bradykinin) that are released via the classical or alternative pathways. Complement component increase vascular permeability, activate leukocytes and induce mast-cell degranulation (41-43). Also, they work as a potent chemotactic factor for neutrophils and mononuclear phagocytes.

\section{Vasoactive amines}

Vasoactive amines are amino groups such as histamine or serotonin, derived from decarboxylation of amino acid histidine that alter the permeability of blood vessels or cause vasodilation. Histamine is produced by mast cells, basophils and circulating platelets in response to heat, cold, irradiation, trauma injury or immune reactions (44-46). Histamine increases the vascular permeability by increasing the blood flow and disrupting the endothelial barriers. Also, histamine promotes vasodilatation by inducing the nitric oxide release. It helps in maintaining the acutephase response during inflammation $(45,47)$. Histamine is shown to induce the proliferation of several cancer cells including BC (48-50). Histamine receptors that aid in cellular proliferation, expressed in vast variety of cancer cells (50,51). Mice lacking histamine H4 receptor (H4R$\mathrm{KO})$ show reduced breast tumor size and weight, decreased number of lung metastases reduced percentage of $\mathrm{CD}^{+}$ tumor-infiltrating $\mathrm{T}$ cells, indicating that histamine receptor is associated with $\mathrm{BC}$ progression and regulates antitumor immunity (52). Another vasoactive amine, serotonin is produced by decarboxylation of tryptophan within enterochromaffin cells of the intestine and released into the bloodstream. It is stored in the platelets and mast cells. Platelets stores serotonin is secreted upon activation at the site of thrombus formation or inflammation $(53,54)$. The actions of serotonin and similar to histamine but they are less potent. Serotonin also exhibit cancer cell growth stimulatory effects and suggested to be involved in tumor cell migration, metastasis and tumor angiogenesis $(55,56)$. One of the mechanisms through serotonin exerts its effects on tumor progression by increasing the blood supply to tumors (55).

\section{Cytokines}

Cytokines are a large group of proteins that are produced by a broad range of cells, including immune cells, endothelial cells, stromal cells, and cancer cells that mediate important biological processes such as growth, proliferation and mobilization of cells. Cytokines modulate the biological activities of multiple cell types, however, they are of particularly important due to their role in regulation of the immune system to coordinate and control the inflammatory response to pathogens (57-60). They are the core components of the inflammatory milieu and play an important role in mediating innate and adaptive immune responses. They help in the recruitment and activation of leukocytes, increase cytotoxicity of natural killer (NK) cells and enhance proliferation of $\mathrm{B}$ and $\mathrm{T}$ cells $(58,60,61)$. Interleukin-1 (IL-1), IL-6, IL-12 and IL-33, resistin, tumor necrosis factor alpha (TNF- $\alpha)$, granulocyte-macrophage colony stimulating factor (GM-CSF) and interferon gamma (IFN- $\gamma$ ) are important inflammatory cytokines among several others.

\section{Hormones}

Hormones are chemical messengers produced by different cell types that regulate the homeostasis of the body and the cross-talk between the cardiovascular, endocrine, and immune systems. In the early 1990s, Garcia-Leme et al. demonstrated that hormone receptors are expressed at reactive structures in inflamed areas where hormone molecules bind and generate signals affecting cell functions important for the development of inflammatory responses, thus suggesting that inflammation is not only a local response but also a hormone-controlled process (62). 


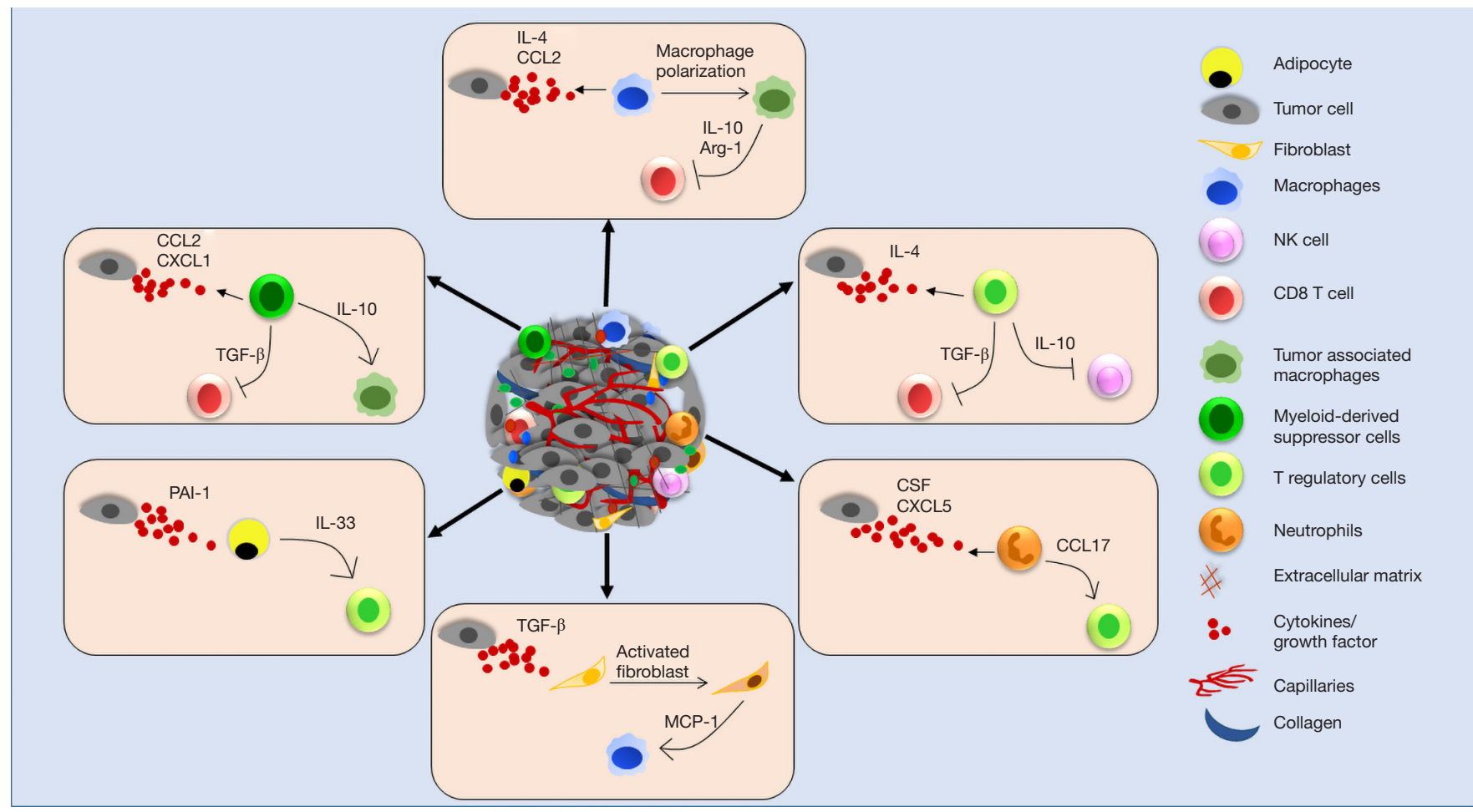

Figure 2 Schematic representation of the components of the inflammatory tumor microenvironment. Tumor-derived soluble factors induce mobilization and reprogramming of immune cells and activation of stromal cells in the tumor-adjacent extracellular matrix. Cytokines and/ or growth factors secreted by these immune or stromal cells further regulate the activity of recruited immune cells leading to the sustenance of tumor favoring inflammatory tumor microenvironment. IL, interleukin; TGF- $\beta$, transforming growth factor $\beta$; MCP-1, monocyte chemoattractant protein-1; CSF, colony stimulating factor; NK, natural killer; PAI-1, plasminogen activator inhibitor-1; Arg-1, arginase 1.

Leptin, a hormone predominantly made by adipose cells was shown to reverse the immunosuppressive effects of acute starvation in mice model (63). In hyperleptinemia, chronic low-grade inflammation was observed via elevation of the production of IL-1, IL-6, IL-12, and TNF- $\alpha$ (64). Elevated expression of leptin in serum and its receptor in human BC cells were associated with BC risk $(65,66)$. Leptin treatment significantly induces the proliferation of T47-D BC cell line (67). Moreover, leptin-induced cell signaling axis is suggested to be involved in the increased risk for cancer development (68). Cortisol is another hormone which has been extensively studied for its role in immune function and the body's anti-inflammatory processes. Alteration in cortisol has been suggested to cause acute proinflammatory stress response resulting in extensive inflammation (69). Significant advances have been made in understanding the molecular mechanisms by which cortisol regulates inflammation and inflammatory diseases (70). It has been demonstrated that corticosteroids regulate the expression of various inflammatory genes such as annexin-1

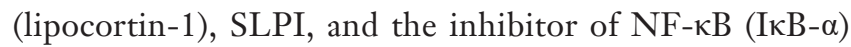
(70-72). Importantly, activation of glucocorticoid receptor is suggested to be increase $\mathrm{BC}$ metastasis (73).

\section{Role of inflammation in tumor immune microenvironment}

Immune cells [macrophages, dendritic cells, T cells, myeloid-derived suppressor cells (MDSCs), etc.] are an important component of the TME that greatly impact tumor development and therapeutic outcomes (74-76). Tumor cells and residing non-tumor cells in the TME build up tumor supportive immune microenvironment by releasing soluble factors such as cytokines, growth factors and hormones (76-78). Interaction of these factors with receptors present on the immune cells determines the mobilization of immune cells into the TME and their fate (Figure 2). For instance, CCL2 secreted by breast tumor cells promotes the trafficking of CCR $2^{+}$macrophages into 


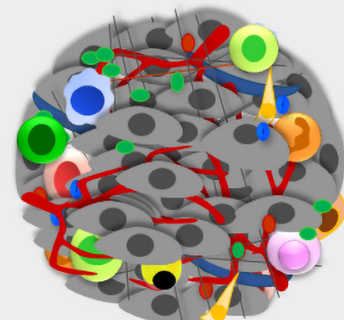

Tumor microenvironment

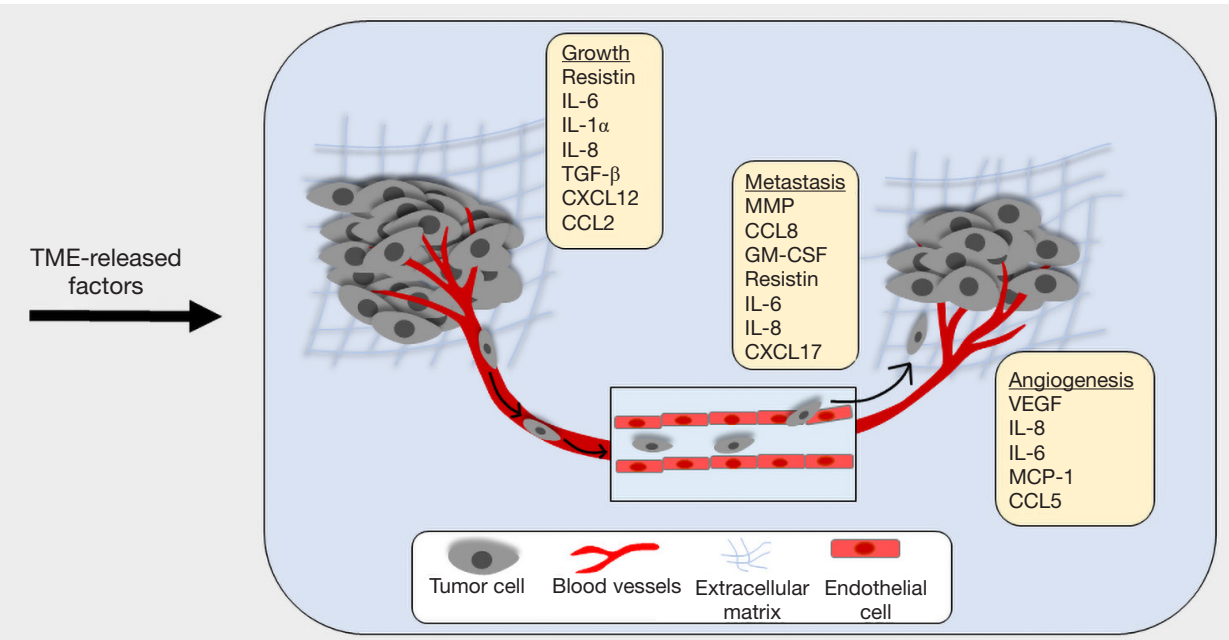

Figure 3 Contribution of inflammatory tumor microenvironment in breast cancer progression. Interaction between the cells in the tumor microenvironment leads to enhanced production of cytokines, growth factors, angiogenic factors and proteolytic enzymes that help in sustaining tumor growth, promoting angiogenesis, and tumor cell invasion and metastasis. IL, interleukin; TGF- $\beta$, transforming growth factor $\beta$; MMP, matrix metalloproteinase; GM-CSF, granulocyte-macrophage colony stimulating factor; MCP-1, monocyte chemoattractant protein-1; VEGF, vascular endothelial growth factor.

the TME (79). Furthermore, it is thought that the diverse chemokine ligand-receptor interactions determine, at least in part, the heterogeneity of immune cell infiltration into the TME. Indeed, some chemokines can bind to multiple receptors (for example CCL5 binds to CCR1, CCR3, CCR5) or conversely a single chemokine receptor can also bind to multiple ligands (for example CCR5 binds to both CCL3 and CCL5). These interactions also help create an immunosuppressed milieu within the TME by maintaining a tumor supportive balance of pro- and anti-tumor immune responses through a complex cellular communication network. Recruitment of MDSCs and macrophages among others in the TME impairs T cell infiltration and/ or favor the accrual and activation of regulatory $\mathrm{T}$ (Treg) cells. Tumour-associated macrophages (TAMs) or M2 macrophages are the most extensively studied and their high density in primary $\mathrm{BC}$ is associated with worse patient prognosis (80-82). M2 polarized macrophages secrete factors (arginase, IL-10, TGF- $\beta$, etc.) to promote an immunosuppressive TME. For example, arginase derived from TAMs can deplete a critical amino acid, arginine, which is crucial for T cell survival and antitumor activities $(16,83,84)$. IL-10 derived from TAMs is also shown to inhibit $\mathrm{T}$ cell proliferation (85). MDSCs present in the TME are shown to promote their immune suppressive activities by upregulation of programmed cell death protein
1 (PD-1), PD-1 ligand 1 (PD-L1), cytotoxic T lymphocyte antigen 4 (CTLA4) on $\mathrm{CD}^{+}$or $\mathrm{CD} 8^{+} \mathrm{T}$ cells (86). Thus, heterocellular interactions facilitated through inflammatory mediators help build immune-suppressive TME to support tumor growth.

\section{Effect of inflammation on breast tumor growth, angiogenesis and metastasis}

Inflammatory TME positively influences tumor growth and metastasis either via direct impact of the factors secreted by the immune cells on the tumor cells or indirectly through their effect on other resident cells within the TME including fibroblasts and endothelial cells (Figure 3). Infiltrated and adipose tissue-resident macrophages are crucial in nurturing the inflammatory TME by releasing several inflammatory cytokines including resistin. Our recent findings demonstrated that the levels of resistin are elevated in $\mathrm{BC}$ patients and support breast tumor cell growth, aggressiveness, and stemness $(87,88)$. In another report, the elevated levels of resistin were shown to positively correlate with breast tumor size and stage, and negatively associated with disease-free and overall survival in BC patients (89). IL-6 release from TAMs is also shown to increase $\mathrm{BC}$ cell proliferation by inducing phosphoinositide 3-kinase (PI3K)-Akt signaling pathway as 
well as apoptosis inhibition through enhancing BCL-2 and decreased BAX expression (90). Also, a positive correlation between increased macrophage index and high vascular grade, and reduced relapse-free survival in BC patients (91). It is shown, TAMs produce pro-angiogenic factor, YKL39, which promotes angiogenesis in BC (92). Also, elevated levels of YKL-39 in tumor mass after neoadjuvant chemotherapy are shown to positively correlate with the increased risk of metastasis and poor clinical responses in patients with BC (92). A positive feedback loop between BC secreted GM-CSF and TAMs produces CCL18, which is suggested to be essential for BC metastasis (93). GMCSF secreted by BC cells polarizes the macrophages to TAM phenotype and in return, TAMs secrete CCL18 to induce EMT and metastasis of BC cells. Furthermore, inhibition of either GM-CSF or CCL18 led to significant reduction of BC metastasis (93). In another report, TAMs were shown to produce matrix metalloproteinases (MMPs), cysteine cathepsins and serine proteases, which degrade and loosen the extracellular matrix (ECM) to support cancer cell invasion (94). TAMs also release proteins such as SPARC and epidermal growth factor (EGF) that promote malignant behavior and metastasis of the breast tumor cells $(95,96)$. In a preclinical mouse model, deletion of intercellular cell adhesion molecule-1 (ICAM-1), which is inversely associated with macrophage infiltration and M2 polarization, inhibited metastatic tumor progression (97). Other crucial cells of breast TME, MDSCs, are also associated with tumor grade, stage and poor prognosis in patients with BC (98). A recent study showed that CXCL17 secreted by lung metastasized BC cells recruits MDSCs and induces the expression of platelet-derived growth factor (PDGF)-BB in them, which in turn, contributes to MDSC-mediated angiogenesis and further supports the colonization of BC cells (99). Along with suppressing the adaptive immune responses, MDSCs also regulate innate immune responses by altering the cytokine secretion of macrophages, which facilitate tumor growth, angiogenesis, and metastasis $(100,101)$.

\section{Effect of inflammation on BC therapy resistance}

Intrinsic or acquired therapy resistance is a significant clinical problem that could occur through a variety of mechanisms (102-104). Inflammatory TME-induced alterations in the gene expression and tumor cell secretome have been recognized as an important mechanism in chemotherapy resistance $(75,105,106)$. We recently demonstrated that inflammatory cytokine, resistin, protected BC cells from doxorubicin-induced cell death through activation of STAT3 (88). Also, IL-6 has been demonstrated to induce stem cell phenotype in BC, and initiate an inflammatory feedback loop of IL-6/STAT3/ Akt/NF- $\mathrm{kB}$, leading to trastuzumab resistance (107). IL-6 confers doxorubicin resistance in $\mathrm{BC}$ by activating the CCAAT enhancer-binding protein, leading to the expression of the downstream genes, such as multidrug resistance-1 (MDR1) (108). Further, several chemotherapeutic drugs are shown to induce the expression of IL-8 and its receptor CXCR1/2 in BC as a counter defense mechanism $(109,110)$. IL-8 confers docetaxel resistance to BC cells through activation of PI3K/Akt and NF- $\mathrm{KB}$ pathways (111). TGF- $\beta 1$ that is often elevated in the plasma of BC patients, is also shown to be associated with increased tumorigenicity and therapy resistance (112). Another report suggested the role of TGF- $\beta$ pathway in epirubicin resistance in BC where it promoted cancer stemness (113). In some studies, mobilization of immune cells to the TME in response to chemotherapy-induced cytokine release is suggested to determine the therapeutic efficacy of treatment. Chemotherapeutic drugs such paclitaxel considerably increases the recruitment of cathepsin-secreting TAM in BC (114). These macrophages-released cathepsin proteases, partially cathepsins B and S, prevent paclitaxel-induced breast tumor cell death. Importantly, combining paclitaxel with cathepsin inhibition significantly increased the therapeutic efficacy in primary and metastatic breast tumors (114).

\section{Targeting of inflammatory pathways for the management of BC}

Strategies to intervene inflammation have been and are being sincerely investigated for cancer management. Multiple preclinical studies have reported the inhibitory effect of nonsteroidal anti-inflammatory drugs (NSAIDs) against mammary carcinogenesis (115-118). In an observational study of the prospective Women's Health Initiative data, Harris and coworkers (2003) examined the effects of the usage of ibuprofen, aspirin, and acetaminophen on $\mathrm{BC}$ risk. Their investigation revealed that the regular use of NSAID for 5-9 years resulted in the reduction of $\mathrm{BC}$ incidence by $21 \%$ and its usage for 10 or more years decreased the incidence by $28 \%$ (119). Further, the deep analysis indicated that the risk reduction in the group using ibuprofen in long-term was greater than that for aspirin, while no relation between acetaminophen use 
and $\mathrm{BC}$ incidence was observed. In a rat model, where rats were fed Ibuprofen prior to mammary tumor development, only $74 \%$ rats developed tumors as compared to $86 \%$ tumor incidence in control rats (116). Apart from NSAIDs, anti-oxidants have also been suggested as chemopreventive agents. A population-based case-control study, where correlation between antioxidants and BC risk was examined, suggested that the long-term supplementation (10 years or more) of multiple vitamins, vitamin $\mathrm{C}$, vitamin $\mathrm{E}$, betacarotene, and zinc in postmenopausal women was effective in prevention of BC development (120).

In multiple studies, application of neutralizing antibodies for tumor-promoting cytokines and/or chemokines, smallmolecule inhibitors of chemokines/receptor signaling, and selective depletion of tumor supportive immune suppressive cells is suggested to be a potential strategy for BC treatment. CXCR1/2 antagonists, AZD5069 and reparixin, are being evaluated in the early phase of the clinical trial to impede granulocyte recruitment to tumors (121). CXCR1/2 receptor-expressing inflammatory immune cells are recruited to breast TME by their tumor cell-derived ligand, CXCL8, which in turn help in tumor promotion via reciprocal signaling $(122,123)$. In HER2-negative $\mathrm{BC}$, reparixin (CXCR1/2 inhibitor) in combination with paclitaxel produced favorable responses in a phase I clinical trial (124). A phase II trial is currently ongoing to explore the safety, pharmacokinetics, and biological effects of the reparixin with paclitaxel in a combination therapy (125). High indoleamine 2,3-dioxygenase (IDO) expression in TME is associated with breast tumor growth, metastasis and poor prognosis $(126,127)$. A clinical trial is exploring the efficacy of chemotherapy (docetaxel or paclitaxel) with or without the addition of indoximod (IDO inhibitor) in metastatic BC (128). CD47 expressed on cancer cells interacts with signal regulatory protein- $\alpha(\operatorname{SIRP}-\alpha)$ present on the surface of macrophages, which helps in their evasion of phagocytosis (129-131). Overexpression of CD47 in breast tumors is associated with tumor progression, metastasis and poor prognosis (132-134). Preclinical studies have evaluated the efficacy of anti-CD47 therapy and found that the blockade of CD47 inhibited BC growth and enhanced macrophage-mediated clearance of BC cells (135). Another phase II clinical trial study is evaluating the efficacy of PLX3397, a CSF1R antagonist, in combination with eribulin chemotherapy in patients with metastatic BC (136). CSF-1/CSF-1R signaling pathway has been associated with poor prognosis in many cancers including BC $(137,138)$. Inhibition of CSF-1/CSF-1R signaling using a monoclonal antibody is also shown to regulate both the infiltration and function of tumor-infiltrating MDSCs and critically influence the response to CTLA-4 checkpoint immunotherapy (139).

\section{Conclusion and future perspective}

Significant epidemiological, experimental and clinical data now exist to not only support, but convincing prove, an association of inflammation with $\mathrm{BC}$ pathogenesis and therapeutic outcomes. Indeed, emerging data continue to strengthen this association further and provide evidence that local or systemic inflammation may be an important risk factor for breast and other malignancies as well as be an important underlying cause of prevalent cancer disparities. These findings have strongly supported the relevance of inflammation as a clinically significant drug target for cancer prevention and therapy. There are; however, still some gaps that need to be filled before we can take a significant leap forward in clinically exploiting the association of inflammation and cancer. We need to better understand the complex nature of inflammatory and immune cell drivers of cancer-associated local and systemic inflammation. We also need to precisely define the impact of this inflammation and associated immune suppression on therapy-resistance including the drug pharmacokinetics in well-defined diverse sets of cancer populations. It is also required that we define how these changes affect drug availability to the tumor cells, drug activity and utilization, and/or responses resulting from changes in drug target excess and accessibility. On a positive note, we now have well-annotated clinical datasets available to us in addition to the state-of-the-art technology (high throughput approaches and automated systems, etc.) that can help us address these important questions. Cancer is a significant clinical problem and many investigational drugs fail in clinical trials. Having established a role of inflammation in therapeutic outcome will help us develop newer and more effective combination therapeutic approaches. In addition to identification of actionable drug targets, future research could also help develop clinical tests for risk prediction, early diagnosis and therapeutic planning. Clearly, we have significantly advanced our understanding of pathobiological association of inflammation with cancer through years of research. We can very well anticipate that novel clinical management approaches will emerge from this knowledge to improve the life-expectancy of cancer patients and impact the quality of life for patients. 


\section{Acknowledgments}

Funding: We would like to acknowledge the funding support from National Institute of Health/National Cancer Institute [CA204801, CA231925 (to S Singh) and CA175772, CA185490, CA224306 (to AP Singh)] and the University of South Alabama Mitchell Cancer Institute.

\section{Footnote}

Conflicts of Interest: AP Singh and S Singh are co-founders, and serve on the executive management team of Tatva Biosciences. SK Srivastava serves as the Director of Cell Biology and Genetics at Tatva Biosciences. The other authors have no conflicts of interest to declare.

Ethical Statement: The authors are accountable for all aspects of the work in ensuring that questions related to the accuracy or integrity of any part of the work are appropriately investigated and resolved.

\section{References}

1. Bray F, Ferlay J, Soerjomataram I, et al. Global cancer statistics 2018: GLOBOCAN estimates of incidence and mortality worldwide for 36 cancers in 185 countries. CA Cancer J Clin 2018;68:394-424.

2. Siegel RL, Miller KD, Jemal A. Cancer statistics, 2019. CA Cancer J Clin 2019;69:7-34.

3. Anders CK, Johnson R, Litton J, et al. Breast cancer before age 40 years. Semin Oncol 2009;36:237-49.

4. Chen HL, Zhou MQ, Tian W, et al. Effect of Age on Breast Cancer Patient Prognoses: A PopulationBased Study Using the SEER 18 Database. PLoS One 2016;11:e165409.

5. VanderWalde A, Hurria A. Early breast cancer in the older woman. Clin Geriatr Med 2012;28:73-91.

6. Deshmukh SK, Azim S, Ahmad A, et al. Biological basis of cancer health disparities: resources and challenges for research. Am J Cancer Res 2017;7:1-12.

7. Williams F, Thompson E. Disparities in Breast Cancer Stage at Diagnosis: Importance of Race, Poverty, and Age. J Health Dispar Res Pract 2017;10:34-45.

8. Bertrand KA, Bethea TN, Adams-Campbell LL, et al. Differential Patterns of Risk Factors for Early-Onset Breast Cancer by ER Status in African American Women. Cancer Epidemiol Biomarkers Prev 2017;26:270-7.

9. Newman LA. Breast cancer in African-American women.
Oncologist 2005;10:1-14.

10. DeSantis CE, Miller KD, Goding Sauer A, et al. Cancer statistics for African Americans, 2019. CA Cancer J Clin 2019;69:211-33.

11. Krok-Schoen JL, Fisher JL, Baltic RD, et al. White-Black Differences in Cancer Incidence, Stage at Diagnosis, and Survival among Adults Aged 85 Years and Older in the United States. Cancer Epidemiol Biomarkers Prev 2016;25:1517-23.

12. Yedjou CG, Tchounwou PB, Payton M, et al. Assessing the Racial and Ethnic Disparities in Breast Cancer Mortality in the United States. Int J Environ Res Public Health 2017. doi: 10.3390/ijerph14050486.

13. Kaminska M, Ciszewski T, Lopacka-Szatan K, et al. Breast cancer risk factors. Prz Menopauzalny 2015;14:196-202.

14. Momenimovahed Z, Salehiniya H. Epidemiological characteristics of and risk factors for breast cancer in the world. Breast Cancer (Dove Med Press) 2019;11:151-64.

15. Sun YS, Zhao Z, Yang ZN, et al. Risk Factors and Preventions of Breast Cancer. Int J Biol Sci 2017;13:1387-97.

16. Allen MD, Jones LJ. The role of inflammation in progression of breast cancer: Friend or foe? (Review). Int J Oncol 2015;47:797-805.

17. Crespi E, Bottai G, Santarpia L. Role of inflammation in obesity-related breast cancer. Curr Opin Pharmacol 2016;31:114-22.

18. Mittal S, Brown NJ, Holen I. The breast tumor microenvironment: role in cancer development, progression and response to therapy. Expert Rev Mol Diagn 2018;18:227-43.

19. Soysal SD, Tzankov A, Muenst SE. Role of the Tumor Microenvironment in Breast Cancer. Pathobiology 2015;82:142-52.

20. Polyak K. Heterogeneity in breast cancer. J Clin Invest 2011;121:3786-8.

21. Turashvili G, Brogi E. Tumor Heterogeneity in Breast Cancer. Front Med (Lausanne) 2017;4:227.

22. Arps DP, Healy P, Zhao L, et al. Invasive ductal carcinoma with lobular features: a comparison study to invasive ductal and invasive lobular carcinomas of the breast. Breast Cancer Res Treat 2013;138:719-26.

23. Obeng-Gyasi S, Ong C, Hwang ES. Contemporary management of ductal carcinoma in situ and lobular carcinoma in situ. Chin Clin Oncol 2016;5:32.

24. Wen HY, Brogi E. Lobular Carcinoma In Situ. Surg Pathol Clin 2018;11:123-45.

25. Allred DC. Ductal carcinoma in situ: terminology, 
classification, and natural history. J Natl Cancer Inst Monogr 2010;2010:134-8.

26. Malhotra GK, Zhao X, Band H, et al. Histological, molecular and functional subtypes of breast cancers. Cancer Biol Ther 2010;10:955-60.

27. Gump FE. Lobular carcinoma in situ (LCIS): pathology and treatment. J Cell Biochem Suppl 1993;17G:53-8.

28. Makki J. Diversity of Breast Carcinoma: Histological Subtypes and Clinical Relevance. Clin Med Insights Pathol 2015;8:23-31.

29. Zangouri VM, Akrami MM, Tahmasebi SM, et al. Medullary Breast Carcinoma and Invasive Ductal Carcinoma: A Review Study. Iran J Med Sci 2018;43:365-71.

30. Onitilo AA, Engel JM, Greenlee RT, et al. Breast cancer subtypes based on ER/PR and Her2 expression: comparison of clinicopathologic features and survival. Clin Med Res 2009;7:4-13.

31. Kondov B, Milenkovikj Z, Kondov G, et al. Presentation of the Molecular Subtypes of Breast Cancer Detected By Immunohistochemistry in Surgically Treated Patients. Open Access Maced J Med Sci 2018;6:961-7.

32. Provenzano E, Ulaner GA, Chin SF. Molecular Classification of Breast Cancer. PET Clin 2018;13:325-38.

33. Dai $X, \mathrm{Li} T$, Bai $Z$, et al. Breast cancer intrinsic subtype classification, clinical use and future trends. Am J Cancer Res 2015;5:2929-43.

34. Molecular Subtypes of Breast Cancer. Breastcancer. org. 2019. Available online: https://www.breastcancer. org/symptoms/types/molecular-subtypes. Accessed 08/30/2019 2019.

35. Dieterich M, Stubert J, Reimer T, et al. Influence of lifestyle factors on breast cancer risk. Breast Care (Basel) 2014;9:407-14.

36. Hashemi SH, Karimi S, Mahboobi H. Lifestyle changes for prevention of breast cancer. Electron Physician 2014;6:894-905.

37. Seiler A, Chen MA, Brown RL, et al. Obesity, Dietary Factors, Nutrition, and Breast Cancer Risk. Curr Breast Cancer Rep 2018;10:14-27.

38. Mamouch F, Berrada N, Aoullay Z, et al. Inflammatory Breast Cancer: A Literature Review. World J Oncol 2018;9:129-35.

39. Robertson FM, Bondy M, Yang W, et al. Inflammatory breast cancer: the disease, the biology, the treatment. CA Cancer J Clin 2010;60:351-75.

40. van Uden DJ, van Laarhoven HW, Westenberg AH, et al. Inflammatory breast cancer: an overview. Crit Rev Oncol
Hematol 2015;93:116-26.

41. Bossi F, Peerschke EI, Ghebrehiwet B, et al. Cross-talk between the complement and the kinin system in vascular permeability. Immunol Lett 2011;140:7-13.

42. Noris M, Remuzzi G. Overview of complement activation and regulation. Semin Nephrol 2013;33:479-92.

43. Sarma JV, Ward PA. The complement system. Cell Tissue Res 2011;343:227-35.

44. Borriello F, Iannone R, Marone G. Histamine Release from Mast Cells and Basophils. Handb Exp Pharmacol 2017;241:121-39.

45. Branco ACCC, Yoshikawa FSY, Pietrobon AJ, et al. Role of Histamine in Modulating the Immune Response and Inflammation. Mediators Inflamm 2018;2018:9524075.

46. Lieberman P. The basics of histamine biology. Ann Allergy Asthma Immunol 2011;106:S2-5.

47. Sciberras DG, Jordan S, Gill D, et al. The role of histamine in the acute inflammatory responses to intradermal platelet activating factor. $\mathrm{Br} \mathrm{J}$ Clin Pharmacol 1991;32:85-90.

48. Cricco GP, Mohamad NA, Sambuco LA, et al. Histamine regulates pancreatic carcinoma cell growth through $\mathrm{H} 3$ and H4 receptors. Inflamm Res 2008;57 Suppl 1:S23-4.

49. Lampiasi N, Azzolina A, Montalto G, et al. Histamine and spontaneously released mast cell granules affect the cell growth of human hepatocellular carcinoma cells. Exp Mol Med 2007;39:284-94.

50. Medina V, Croci M, Crescenti E, et al. The role of histamine in human mammary carcinogenesis: $\mathrm{H} 3$ and $\mathrm{H} 4$ receptors as potential therapeutic targets for breast cancer treatment. Cancer Biol Ther 2008;7:28-35.

51. Medina VA, Rivera ES. Histamine receptors and cancer pharmacology. Br J Pharmacol 2010;161:755-67.

52. Sterle HA, Nicoud MB, Massari NA, et al. Immunomodulatory role of histamine $\mathrm{H} 4$ receptor in breast cancer. Br J Cancer 2019;120:128-38.

53. Duerschmied D, Canault M, Lievens D, et al. Serotonin stimulates platelet receptor shedding by tumor necrosis factor-alpha-converting enzyme (ADAM17). J Thromb Haemost 2009;7:1163-71.

54. Mossner R, Lesch KP. Role of serotonin in the immune system and in neuroimmune interactions. Brain Behav Immun 1998;12:249-71.

55. Sarrouilhe D, Clarhaut J, Defamie N, et al. Serotonin and cancer: what is the link? Curr Mol Med 2015;15:62-77.

56. Sarrouilhe D, Mesnil M. Serotonin and human cancer: A critical view. Biochimie 2019;161:46-50.

57. Condotta SA, Richer MJ. The immune battlefield: 
The impact of inflammatory cytokines on CD8+ T-cell immunity. PLoS Pathog 2017;13:e1006618.

58. Dinarello CA. Proinflammatory cytokines. Chest 2000;118:503-8

59. Feghali CA, Wright TM. Cytokines in acute and chronic inflammation. Front Biosci 1997;2:d12-26.

60. Van der Meide PH, Schellekens H. Cytokines and the immune response. Biotherapy 1996;8:243-9.

61. Sprent J, Zhang X, Sun S, et al. T-cell proliferation in vivo and the role of cytokines. Philos Trans R Soc Lond B Biol Sci 2000;355:317-22.

62. Garcia-Leme J, Farsky SP. Hormonal control of inflammatory responses. Mediators Inflamm 1993;2:181-98.

63. Lord GM, Matarese G, Howard JK, et al. Leptin modulates the T-cell immune response and reverses starvation-induced immunosuppression. Nature 1998;394:897-901.

64. Carbone F, La Rocca C, Matarese G. Immunological functions of leptin and adiponectin. Biochimie 2012;94:2082-8.

65. Ishikawa M, Kitayama J, Nagawa H. Enhanced expression of leptin and leptin receptor (OB-R) in human breast cancer. Clin Cancer Res 2004;10:4325-31.

66. Pan H, Deng LL, Cui JQ, et al. Association between serum leptin levels and breast cancer risk: An updated systematic review and meta-analysis. Medicine (Baltimore) 2018;97:e11345.

67. Laud K, Gourdou I, Pessemesse L, et al. Identification of leptin receptors in human breast cancer: functional activity in the T47-D breast cancer cell line. Mol Cell Endocrinol 2002;188:219-26.

68. Fenton JI, Hursting SD, Perkins SN, et al. Interleukin-6 production induced by leptin treatment promotes cell proliferation in an Apc (Min/+) colon epithelial cell line. Carcinogenesis 2006;27:1507-15.

69. Hannibal KE, Bishop MD. Chronic stress, cortisol dysfunction, and pain: a psychoneuroendocrine rationale for stress management in pain rehabilitation. Phys Ther 2014;94:1816-25.

70. Barnes PJ. How corticosteroids control inflammation: Quintiles Prize Lecture 2005. Br J Pharmacol 2006;148:245-54.

71. Hall SE, Lim S, Witherden IR, et al. Lung type II cell and macrophage annexin I release: differential effects of two glucocorticoids. Am J Physiol 1999;276:L114-21.

72. Newton R, Hart LA, Stevens DA, et al. Effect of dexamethasone on interleukin-1beta-(IL-1beta)-induced nuclear factor-kappaB (NF-kappaB) and kappaB- dependent transcription in epithelial cells. Eur J Biochem 1998;254:81-9.

73. Obradovic MMS, Hamelin B, Manevski N, et al. Glucocorticoids promote breast cancer metastasis. Nature 2019;567:540-4.

74. Salvatore V, Teti G, Focaroli S, et al. The tumor microenvironment promotes cancer progression and cell migration. Oncotarget 2017;8:9608-16.

75. Sun Y. Tumor microenvironment and cancer therapy resistance. Cancer Lett 2016;380:205-15.

76. Wang M, Zhao J, Zhang L, et al. Role of tumor microenvironment in tumorigenesis. J Cancer 2017;8:761-73.

77. Deshmukh SK, Srivastava SK, Tyagi N, et al. Emerging evidence for the role of differential tumor microenvironment in breast cancer racial disparity: a closer look at the surroundings. Carcinogenesis 2017;38:757-65.

78. Runa F, Hamalian S, Meade K, et al. Tumor microenvironment heterogeneity: challenges and opportunities. Curr Mol Biol Rep 2017;3:218-29.

79. Heiskala M, Leidenius M, Joensuu K, et al. High expression of CCL2 in tumor cells and abundant infiltration with CD14 positive macrophages predict early relapse in breast cancer. Virchows Arch 2019;474:3-12.

80. Pollard JW. Tumour-educated macrophages promote tumour progression and metastasis. Nat Rev Cancer 2004;4:71-8.

81. Qiu SQ, Waaijer SJH, Zwager MC, et al. Tumorassociated macrophages in breast cancer: Innocent bystander or important player? Cancer Treat Rev 2018;70:178-89.

82. Zhao X, Qu J, Sun Y, et al. Prognostic significance of tumor-associated macrophages in breast cancer: a metaanalysis of the literature. Oncotarget 2017;8:30576-86.

83. Noy R, Pollard JW. Tumor-associated macrophages: from mechanisms to therapy. Immunity 2014;41:49-61.

84. Takahashi H, Sakakura K, Kudo T, et al. Cancerassociated fibroblasts promote an immunosuppressive microenvironment through the induction and accumulation of protumoral macrophages. Oncotarget 2017;8:8633-47.

85. Muthuswamy R, Okada NJ, Jenkins FJ, et al. Epinephrine promotes COX-2-dependent immune suppression in myeloid cells and cancer tissues. Brain Behav Immun 2017;62:78-86.

86. Zhu H, Gu Y, Xue Y, et al. CXCR2(+) MDSCs promote breast cancer progression by inducing EMT and activated T cell exhaustion. Oncotarget 2017;8:114554-67. 
87. Deshmukh SK, Srivastava SK, Bhardwaj A, et al. Resistin and interleukin-6 exhibit racially-disparate expression in breast cancer patients, display molecular association and promote growth and aggressiveness of tumor cells through STAT3 activation. Oncotarget 2015;6:11231-41.

88. Deshmukh SK, Srivastava SK, Zubair H, et al. Resistin potentiates chemoresistance and stemness of breast cancer cells: Implications for racially disparate therapeutic outcomes. Cancer Lett 2017;396:21-9.

89. Lee YC, Chen YJ, Wu CC, et al. Resistin expression in breast cancer tissue as a marker of prognosis and hormone therapy stratification. Gynecol Oncol 2012;125:742-50.

90. Li H, Yang B, Huang J, et al. Cyclooxygenase-2 in tumorassociated macrophages promotes breast cancer cell survival by triggering a positive-feedback loop between macrophages and cancer cells. Oncotarget 2015;6:29637-50.

91. Leek RD, Lewis CE, Whitehouse R, et al. Association of macrophage infiltration with angiogenesis and prognosis in invasive breast carcinoma. Cancer Res 1996;56:4625-9.

92. Liu T, Larionova I, Litviakov N, et al. Tumor-associated macrophages in human breast cancer produce new monocyte attracting and pro-angiogenic factor YKL39 indicative for increased metastasis after neoadjuvant chemotherapy. Oncoimmunology 2018;7:e1436922.

93. Su S, Liu Q, Chen J, et al. A positive feedback loop between mesenchymal-like cancer cells and macrophages is essential to breast cancer metastasis. Cancer Cell 2014;25:605-20.

94. Joyce JA, Pollard JW. Microenvironmental regulation of metastasis. Nat Rev Cancer 2009;9:239-52.

95. Sangaletti S, Di Carlo E, Gariboldi S, et al. Macrophage-derived SPARC bridges tumor cellextracellular matrix interactions toward metastasis. Cancer Res 2008;68:9050-9.

96. Wyckoff J, Wang W, Lin EY, et al. A paracrine loop between tumor cells and macrophages is required for tumor cell migration in mammary tumors. Cancer Res 2004;64:7022-9.

97. Yang M, Liu J, Piao C, et al. ICAM-1 suppresses tumor metastasis by inhibiting macrophage M2 polarization through blockade of efferocytosis. Cell Death Dis 2015;6:e1780.

98. Gonda K, Shibata M, Ohtake T, et al. Myeloid-derived suppressor cells are increased and correlated with type 2 immune responses, malnutrition, inflammation, and poor prognosis in patients with breast cancer. Oncol Lett 2017;14:1766-74.

99. Hsu YL, Yen MC, Chang WA, et al. CXCL17-derived
CD11b(+)Gr-1(+) myeloid-derived suppressor cells contribute to lung metastasis of breast cancer through platelet-derived growth factor-BB. Breast Cancer Res 2019;21:23.

100. Ostrand-Rosenberg S, Sinha P, Beury DW, et al. Crosstalk between myeloid-derived suppressor cells (MDSC), macrophages, and dendritic cells enhances tumor-induced immune suppression. Semin Cancer Biol 2012;22:275-81.

101.Sinha P, Clements VK, Bunt SK, et al. Cross-talk between myeloid-derived suppressor cells and macrophages subverts tumor immunity toward a type 2 response. J Immunol 2007;179:977-83.

102. Kelderman S, Schumacher TN, Haanen JB. Acquired and intrinsic resistance in cancer immunotherapy. Mol Oncol 2014;8:1132-9.

103.Lippert TH, Ruoff HJ, Volm M. Intrinsic and acquired drug resistance in malignant tumors. The main reason for therapeutic failure. Arzneimittelforschung 2008;58:261-4.

104. Mansoori B, Mohammadi A, Davudian S, et al. The Different Mechanisms of Cancer Drug Resistance: A Brief Review. Adv Pharm Bull 2017;7:339-48.

105.Klemm F, Joyce JA. Microenvironmental regulation of therapeutic response in cancer. Trends Cell Biol 2015;25:198-213.

106. Son B, Lee S, Youn H, et al. The role of tumor microenvironment in therapeutic resistance. Oncotarget 2017;8:3933-45.

107. Korkaya H, Kim GI, Davis A, et al. Activation of an IL6 inflammatory loop mediates trastuzumab resistance in HER 2 + breast cancer by expanding the cancer stem cell population. Mol Cell 2012;47:570-84.

108. Conze D, Weiss L, Regen PS, et al. Autocrine production of interleukin 6 causes multidrug resistance in breast cancer cells. Cancer Res 2001;61:8851-8.

109.De Larco JE, Wuertz BR, Manivel JC, et al. Progression and enhancement of metastatic potential after exposure of tumor cells to chemotherapeutic agents. Cancer Res 2001;61:2857-61.

110.Shi Z, Yang WM, Chen LP, et al. Enhanced chemosensitization in multidrug-resistant human breast cancer cells by inhibition of IL-6 and IL-8 production. Breast Cancer Res Treat 2012;135:737-47.

111. Shao N, Chen LH, Ye RY, et al. The depletion of interleukin-8 causes cell cycle arrest and increases the efficacy of docetaxel in breast cancer cells. Biochem Biophys Res Commun 2013;431:535-41.

112. Teicher BA. Malignant cells, directors of the malignant process: role of transforming growth factor-beta. Cancer 
Metastasis Rev 2001;20:133-43.

113. O'Brien SK, Chen L, Zhong W, et al. Breast cancer cells respond differentially to modulation of TGFbeta2 signaling after exposure to chemotherapy or hypoxia. Cancer Res 2015;75:4605-16.

114. Shree T, Olson OC, Elie BT, et al. Macrophages and cathepsin proteases blunt chemotherapeutic response in breast cancer. Genes Dev 2011;25:2465-79.

115.Albert ED, Scholz S. Immunogenetic implications in rheumatic diseases. Acta Rhumatol Belg 1979;3:121-7.

116. Alshafie GA, Harris RE, Robertson FM, et al. Comparative chemopreventive activity of ibuprofen and $\mathrm{N}$-(4-hydroxyphenyl) retinamide against the development and growth of rat mammary adenocarcinomas. Anticancer Res 1999;19:3031-6.

117. Carter CA, Ip MM, Ip C. A comparison of the effects of the prostaglandin synthesis inhibitors indomethacin and carprofen on 7,12-dimethylbenz[a] anthracene-induced mammary tumorigenesis in rats fed different amounts of essential fatty acid. Carcinogenesis 1989;10:1369-74.

118. Steele VE, Moon RC, Lubet RA, et al. Preclinical efficacy evaluation of potential chemopreventive agents in animal carcinogenesis models: methods and results from the NCI Chemoprevention Drug Development Program. J Cell Biochem Suppl 1994;20:32-54.

119. Harris RE, Chlebowski RT, Jackson RD, et al. Breast cancer and nonsteroidal anti-inflammatory drugs: prospective results from the Women's Health Initiative. Cancer Res 2003;63:6096-101.

120.Pan SY, Zhou J, Gibbons L, et al. Antioxidants and breast cancer risk- a population-based case-control study in Canada. BMC Cancer 2011;11:372.

121.Phase Ib/II Study of MEDI4736 Evaluated in Different Combinations in Metastatic Pancreatic Ductal Carcinoma. Available online: https://ClinicalTrials.gov/show/ NCT02583477

122.Ha H, Debnath B, Neamati N. Role of the CXCL8CXCR1/2 Axis in Cancer and Inflammatory Diseases. Theranostics 2017;7:1543-88.

123. Todorovic-Rakovic N, Milovanovic J. Interleukin-8 in breast cancer progression. J Interferon Cytokine Res 2013;33:563-70.

124.Pilot Study to Evaluate Reparixin With Weekly Paclitaxel in Patients With HER 2 Negative Metastatic Breast Cancer (MBC). Available online: https://ClinicalTrials. gov/show/NCT02001974

125.A Double-blind Study of Paclitaxel in Combination With Reparixin or Placebo for Metastatic Triple-Negative Breast
Cancer. Available online: https://ClinicalTrials.gov/show/ NCT02370238

126. Asghar K, Loya A, Rana IA, et al. Indoleamine 2,3-dioxygenase expression and overall survival in patients diagnosed with breast cancer in Pakistan. Cancer Manag Res 2019;11:475-81.

127. Chen JY, Li CF, Kuo CC, et al. Cancer/stroma interplay via cyclooxygenase-2 and indoleamine 2,3-dioxygenase promotes breast cancer progression. Breast Cancer Res 2014;16:410.

128. Study of Chemotherapy in Combination With IDO Inhibitor in Metastatic Breast Cancer. Available online: https://ClinicalTrials.gov/show/NCT01792050

129. Brightwell RM, Grzankowski KS, Lele S, et al. The CD47 "don't eat me signal" is highly expressed in human ovarian cancer. Gynecol Oncol 2016;143:393-7.

130.Russ A, Hua AB, Montfort WR, et al. Blocking "don't eat me" signal of CD47-SIRPalpha in hematological malignancies, an in-depth review. Blood Rev 2018;32:480-9.

131. Smolle MA, Pichler M. Inflammation, phagocytosis and cancer: another step in the CD47 act. J Thorac Dis 2017;9:2279-82.

132. Baccelli I, Stenzinger A, Vogel V, et al. Co-expression of MET and CD47 is a novel prognosticator for survival of luminal breast cancer patients. Oncotarget 2014;5:8147-60.

133. Nagahara M, Mimori K, Kataoka A, et al. Correlated expression of CD47 and SIRPA in bone marrow and in peripheral blood predicts recurrence in breast cancer patients. Clin Cancer Res 2010;16:4625-35.

134.Zhang H, Lu H, Xiang L, et al. HIF-1 regulates CD47 expression in breast cancer cells to promote evasion of phagocytosis and maintenance of cancer stem cells. Proc Natl Acad Sci U S A 2015;112:E6215-23.

135.Feliz-Mosquea YR, Christensen AA, Wilson AS, et al. Combination of anthracyclines and anti-CD47 therapy inhibit invasive breast cancer growth while preventing cardiac toxicity by regulation of autophagy. Breast Cancer Res Treat 2018;172:69-82.

136. Phase Ib/II Study of PLX 3397 and Eribulin in Patients With Metastatic Breast Cancer. Available online: https:// ClinicalTrials.gov/show/NCT01596751

137. Richardsen E, Uglehus RD, Johnsen SH, et al. Macrophage-colony stimulating factor (CSF1) predicts breast cancer progression and mortality. Anticancer Res 2015;35:865-74.

138. Swierczak A, Cook AD, Lenzo JC, et al. The promotion of breast cancer metastasis caused by inhibition of CSF- 
Page 14 of 14

1R/CSF-1 signaling is blocked by targeting the G-CSF receptor. Cancer Immunol Res 2014;2:765-76.

139. Holmgaard RB, Brachfeld A, Gasmi B, et al. Timing
Deshmukh et al. Role of inflammation in $\mathrm{BC}$ progression

of CSF-1/CSF-1R signaling blockade is critical to improving responses to CTLA-4 based immunotherapy. Oncoimmunology 2016;5:e1151595.
Cite this article as: Deshmukh SK, Srivastava SK, Poosarla T, Dyess DL, Holliday NP, Singh AP, Singh S. Inflammation, immunosuppressive microenvironment and breast cancer: opportunities for cancer prevention and therapy. Ann Transl Med 2019;7(20):593. doi: 10.21037/atm.2019.09.68 